Article

\title{
Study on the CO Formation Mechanism during Coal Ambient Temperature Oxidation
}

\author{
Shuo Liu ${ }^{1}$, Yuguo $\mathrm{Wu}^{1,2, *}$, Chunshan Zhou ${ }^{1,2}$, Jianming $\mathrm{Wu}^{2}$ and Yulong Zhang ${ }^{1,2}$ \\ 1 College of Safety and Emergency Management Engineering, Taiyuan University of Technology, \\ Taiyuan 030024, China; liushuo89123@163.com (S.L.); zhouchunshan@tyut.edu.cn (C.Z.); \\ zhangyulong@tyut.edu.cn (Y.Z.) \\ 2 Shanxi Engineering Research Center for Mine Ventilation and Fire Prevention, Taiyuan 030024, China; \\ tyutwjm@163.com \\ * Correspondence: tyutwyg@126.com; Tel.: +86-351-6066518
}

Received: 26 April 2020; Accepted: 19 May 2020; Published: 20 May 2020

\begin{abstract}
The $\mathrm{CO}$ formation rules of coal were analyzed by a self-developed testing device under ambient temperature. The changes of functional groups caused by oxidation were obtained using Fourier-transform infrared spectroscopy (FTIR). The experimental results showed that CO was generated during the ambient temperature oxidation. The highest concentration level of $\mathrm{CO}$ could be $389 \mathrm{ppm}$. The methylene and aldehyde groups on the side chains were involved in the reaction. For the quantum mechanical approach, we employed the density functional theory with the 6-31 G $(d, p)$ basis set. Density functional theory-based computations interpreted the possible reaction sites on a coal molecule by electronic static potential analysis. The rationality of the predicted reactions was also evaluated by transition state analysis and energy analysis. This research theoretically proved that coal could be oxidized to carbon monoxide under ambient temperatures and gave the possible reaction paths.
\end{abstract}

Keywords: spontaneous combustion; oxidation of coal; ambient temperature; density functional theory; reaction mechanism; reaction path

\section{Introduction}

$\mathrm{CO}$ is often used as an essential index gas for early prediction of coal spontaneous combustion for its high sensitivity and easy detection [1-4]. According to China's Coal Mine Safety Regulation, underground $\mathrm{CO}$ concentration should not be higher than $24 \mathrm{ppm}$. Otherwise, measures must be taken to prevent coal spontaneous combustion. However, many field practices show that, in the mine area, the $\mathrm{CO}$ concentration often exceeds the standard without apparent signs of spontaneous combustion [5]. Sometimes, $\mathrm{CO}$ can be detected in the mining face or air return way without apparent signs of spontaneous combustion, such as tarry odor, coal wall sweating, and smoking. Therefore, it is of considerable significance for mine safety production to study the mechanism of the spontaneous combustion of coal, especially the mechanism of oxidation to form $\mathrm{CO}$ at low temperatures.

Many researchers have studied the mechanism of coal oxidation at low temperatures [6-8]. By using the method of density functional theory (DFT), Wang and Deng [9] analyzed the change rules of different functional groups in the molecular structure of coal and simulated the physical adsorption, chemical adsorption, and chemical reaction processes of different functional groups of coal with oxygen. Wang Deming et al. [10] described the oxidation mechanism of coal spontaneous combustion by the DFT method. They proposed a series of cyclic chain reactions. Deng Jun [11] found eight index gases of coal spontaneous combustion and corresponding characteristic temperatures by thermal analysis and large-scale experiments on coal spontaneous combustion. 
The oxidation of coal at low temperatures has been well studied. However, there is very little research on the oxidation of coal, especially the formation mechanism of $\mathrm{CO}$ under ambient temperature. Therefore, a study of the $\mathrm{CO}$ formation mechanism during the coal ambient temperature oxidation is necessary. This kind of study can give us a deeper understanding of the initial stages of coal spontaneous combustion. Our previous research has already done some work on the calculation of the CO production rate of coal under ambient temperatures and at critical temperatures [12]. To follow up on the previous research, the demand for this research is to theoretically prove that coal can be oxidized to carbon monoxide under ambient temperature and give the possible reaction paths. In this paper, we investigate the oxidation of Australia White (AW) coal to CO by self-made equipment for coal oxidation under ambient temperature. The changes of functional groups in coal during oxidation under ambient temperature were analyzed by infrared spectroscopy. Density functional theory (DFT)-based computations interpreted the reactive sites and electronic static potential (ESP) on the coal molecule. The rationality of the predicted reaction was also evaluated by the transition state analysis and energy analysis. This study may be helpful to understand the formation mechanism of CO under ambient temperature.

\section{Materials and Methods}

\subsection{Coal Samples}

The coal samples were from an AW coal mine that had shown self-ignition tendencies. Fresh coal samples weighing up to $50 \mathrm{~kg}$ were cut from the working face. The coal samples were then moved to the laboratory. Before the test, the oxide layer on the coal sample surface was stripped. The remaining unoxidized coal samples were crushed and sieved with different particle diameters (2.00 3.35 mm). The proximate analysis and elemental analysis of the coal samples are shown in Table 1.

Table 1. Proximate analysis and elemental analysis of the coal samples from AW coal.

\begin{tabular}{ccccccccc}
\hline \multirow{2}{*}{$\begin{array}{c}\text { R0max } \\
(\%)\end{array}$} & \multicolumn{3}{c}{ Proximate Analysis (w\%) } & \multicolumn{5}{c}{ Elemental Analysis (wdaf\%) } \\
\cline { 2 - 10 } & Mad & Aad & Vdaf & C & H & O* & N & S \\
\hline 3.86 & 0.94 & 10.86 & 12.6 & 87.22 & 3.51 & 6.61 & 1.1 & 1.56 \\
\hline
\end{tabular}

Note: R0max is the maximum reflectance of the vitrinite in coal, Mad is the mass fraction of moisture in the sample on dry air basis, Aad is the mass fraction of ash in the sample on dry air basis, and Vdaf is the mass fraction of volatile matter in the sample on the dry ash-free basis. $\mathrm{w}\left(\mathrm{O}^{*}\right)=1-\mathrm{w}(\mathrm{C})-\mathrm{w}(\mathrm{H})-\mathrm{w}(\mathrm{N})-\mathrm{w}(\mathrm{S})$.

\subsection{Ambient Temperature Oxidation}

The experiment of coal oxidation under ambient temperature was carried out in a hermetically sealed reactor (see Figure 1). The sensors, including carbon monoxide, oxygen, and temperature, were set up and connected to the computer. The testing device consists of a cylindrical chamber with a volume of $1.718 \times 10^{-2} \mathrm{~m}^{3}$ (the height is $350 \mathrm{~mm}$, and the bottom radius is $125 \mathrm{~mm}$ ). The measurement range of the $\mathrm{CO}$ sensor is $0-1000 \mathrm{ppm}$, and the resolution is $1 \mathrm{ppm}$. For the $\mathrm{O}_{2}$ sensor, the measurement range is $0-25 \mathrm{VOL} \%$, and the resolution is $0.1 \mathrm{VOL} \%$. All the data of the sensors were recorded by the computer automatically. In particular, there was no heating part in the reactor. Also, no air can flow in or out of though the device during the reaction. The coal samples were crushed and screened into samples of $2.00 \sim 3.35 \mathrm{~mm}$ particle size, and then the coal samples $(3.5 \mathrm{~kg})$ were sealed into the reaction chamber. The experiment stopped when the concentration of $\mathrm{CO}$ stopped changing. The room temperature was around $15{ }^{\circ} \mathrm{C}$ during the experiment. 


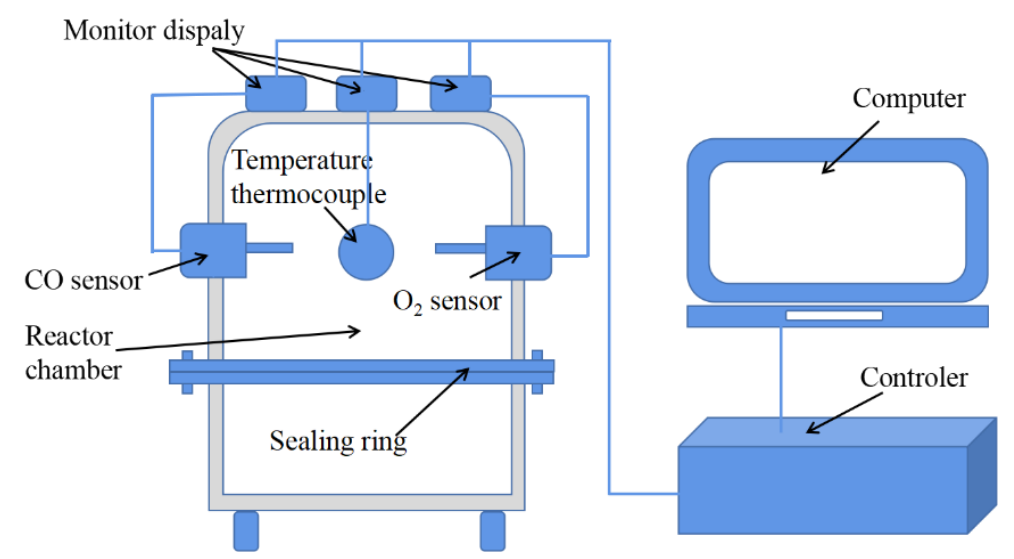

Figure 1. Schematic diagram of the ambient temperature oxidation device.

\subsection{FTIR Study}

The experiments were also carried out using the Fourier-transform infrared spectroscopy (FTIR) (MIRacle 10 SHIMADZU; JPN). The FTIR study can help to obtain a better understanding of coal oxidization to carbon monoxide under ambient temperature. The samples before and after the ambient temperature oxidation were tested respectively for the comparison. Five fresh coal samples (10 g each) were selected for the FTIR test. Another five coal samples (10 g each) were ground into fine particles and placed with the air under ambient temperature. The FTIR test for the second group was conducted after the completion of the ambient temperature oxidation experiment. Functional groups of coal samples before and after the oxidation were obtained, respectively. The test parameters were set as follows: the scan range was $400-4000 \mathrm{~cm}^{-1}$, the resolution was $2 \mathrm{~cm}^{-1}$, and the scan times were 64 .

\subsection{DFT Calculation}

By analyzing the FTIR test results and combining previous studies on the coal oxidation reaction process and mechanism, the possible reaction of AW coal samples during the ambient temperature oxidation process was predicted. The geometries of reactants, products, intermediates, and transition state molecules in the reaction process were optimized using the Gaussian 09 program package with DFT at the level of B3 LYP/6-31 G (d, p). The potential distribution on the surface of the reactant was calculated. Combined with the FTIR experiment results, the reaction locations that may be involved in the oxidation reaction were analyzed. By calculating the energies of reactants, products, intermediates, and transition state molecules, the possibility of the predicted reaction paths was judged from the energy perspective.

\section{Results and Discussion}

\subsection{Ambient Temperature Oxidation Results}

The ambient temperature oxidation experiment consists of two parts: the first oxidation and second oxidation. The primary oxidation lasted for $118 \mathrm{~h}$, and then open the reactor, and refresh the coal samples by the air. The secondary oxidation lasted for $38 \mathrm{~h}$. The experiment results can be seen in Figures 2 and 3. 


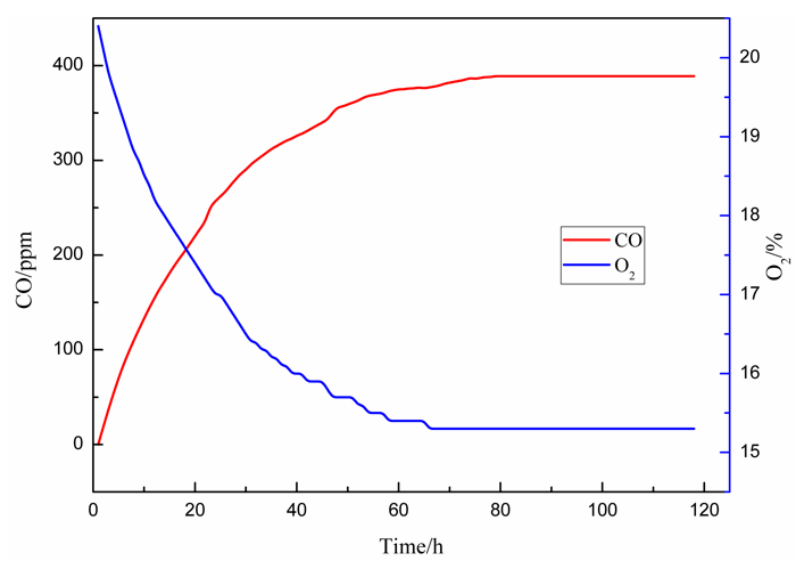

Figure 2. Curves of the first time of ambient temperature oxidation experiment results.

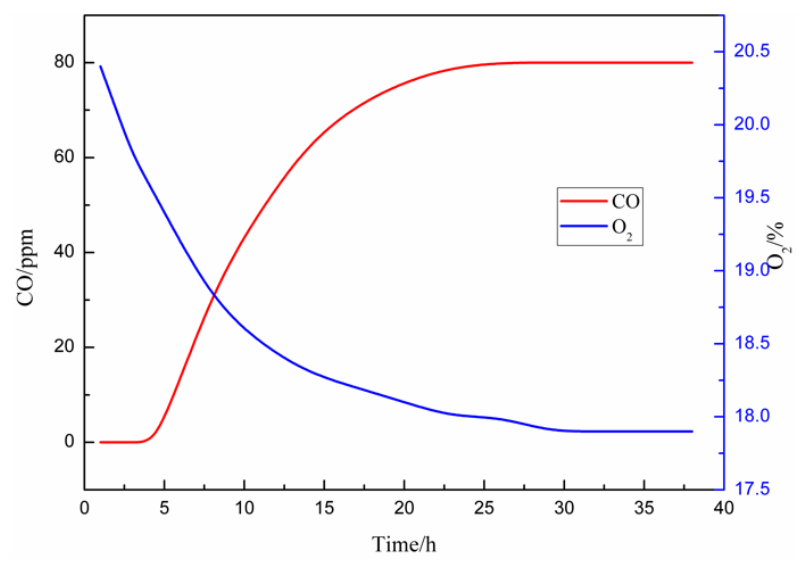

Figure 3. Curves of the second time of ambient temperature oxidation experiment results.

During the primary oxidation, the $\mathrm{CO}$ appeared after $1.5 \mathrm{~h}$. The maximum of $\mathrm{CO}$ concentration level can be $389 \mathrm{ppm}$ after $79 \mathrm{~h}$. CO production leads to $\mathrm{O}_{2}$ consumption. After $66 \mathrm{~h}$, the $\mathrm{O}_{2}$ concentration level reached a minimum of $15.3 \%$. During the secondary oxidation, the CO appeared after $4 \mathrm{~h}$. The maximum CO concentration level can be $80 \mathrm{ppm}$ after $26 \mathrm{~h}$. After $29 \mathrm{~h}$, the reaction stopped and the $\mathrm{O}_{2}$ concentration level reached a minimum of $17.9 \%$.

We can conclude that the coal samples can react with $\mathrm{O}_{2}$ and produce $\mathrm{CO}$ under ambient temperature. The $\mathrm{CO}$ during the primary oxidation appears earlier and have more production than the secondary oxidation.

\subsection{FTIR Analysis}

In the initial stage of coal oxidation, only a small number of active groups participate in the reactions. During the burning stage, a large number of secondary active groups are generated and a chain reaction occurs rapidly, and the reaction strength increases rapidly [13]. The FTIR analysis was further carried out to get more information on the difference in chemical composition during the oxidation processes. By comparing the FTIR test results of coal samples, the functional groups that might be involved in the reaction were inferred.

As shown in Figure 4, several peaks of oxidized coal have changed in the spectrum compared with that of fresh coal. Peaks decreased after oxidation at $3300 \mathrm{~cm}^{-1}, 2860-2920 \mathrm{~cm}^{-1}$, and $1610 \mathrm{~cm}^{-1}$, which could be assigned to the "hydroxyl group $(-\mathrm{OH})$," "stretching vibration of methyl $\left(-\mathrm{CH}_{3}\right)$ asymmetric stretching vibration of methylene $\left(-\mathrm{CH}_{2}\right)$," and "carbonyl group $(\mathrm{C}=\mathrm{O})$." The peak of carboxyl appears around $2321-2400 \mathrm{~cm}^{-1}$ and was strengthened after the oxidation. 


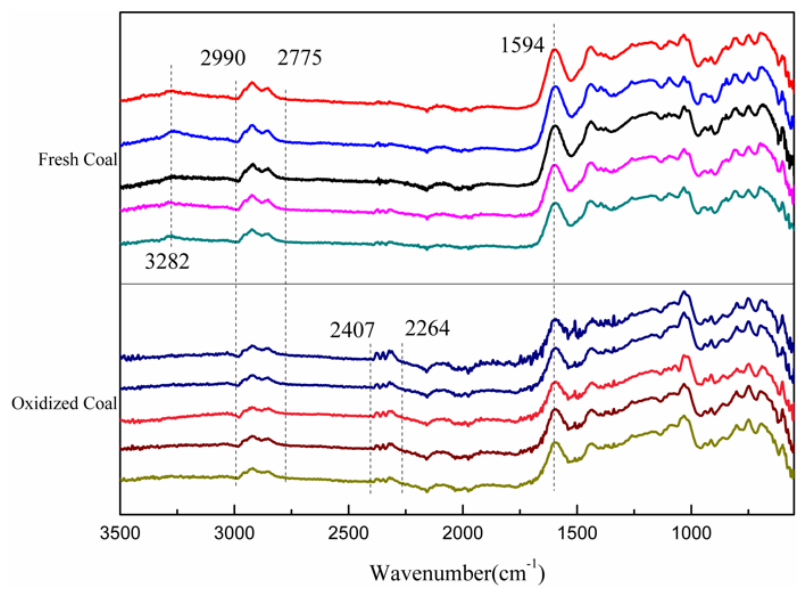

Figure 4. Comparison of infrared experiment results of fresh coal and oxidized coal.

These results indicate that methyl or methylene and carbonyl group in XM coal may react with oxygen under ambient temperature. Evaporation of water from coal also results in the reduction of hydroxyl functional groups. There was no more evidence that the hydroxyl group was involved in oxidation reactions or not. As an important product, the carboxyl group appears in the oxidation reaction of coal under ambient temperature. The carboxyl group plays a significant role during the reaction.

According to the Transition-state theory, a chemical reaction system can be divided into the following three regions: (a) the reactant region, (b) the transition state region, and (c) the product region [14]. A lot of work has been done on the mechanism of oxidation of the active groups in coal molecules. The active groups of coal molecules involved in the oxidation process are divided into bridged bonds and side chains. According to the previous study on the molecular structure of coal [15], it is inferred that the methyl-ether, the alkylidene in bridged bonds, and the methoxyl aldehyde in the side chain are involved in the oxidation progress. Based on the results of previous studies and combine with the FTIR results of this study, the possible reactions to carbon monoxide under ambient temperature are inferred as follows:

Reaction path a:

Step 1.<smiles>Cc1cc2ccc(C(C)O[14C](=O)OC(O)c3cc4cc(CO)ccc4cc3C)cc2cc1C</smiles>

In this step, the chemisorptions take place between $\mathrm{O}_{2}$ and reactant 1 (R1) and produce the intermediate $\left(\mathrm{M}_{1}\right)$.

Step 2.

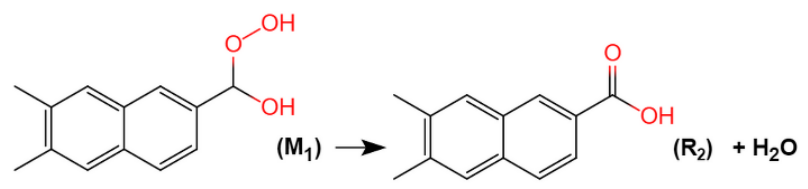

The intermediate $\left(\mathrm{M}_{1}\right)$ creates $\mathrm{H}_{2} \mathrm{O}$ and reactant $2\left(\mathrm{R}_{2}\right)$ with the carboxy group.

Step 3.<smiles>Cc1cc2ccc(C(=O)O)cc2cc1CC(C)C(=O)O</smiles> 
The reactant $2\left(\mathrm{R}_{2}\right)$ decomposes into product $1\left(\mathrm{P}_{1}\right)$ and $\mathrm{CO}$.

Reaction path $\mathrm{b}$ :

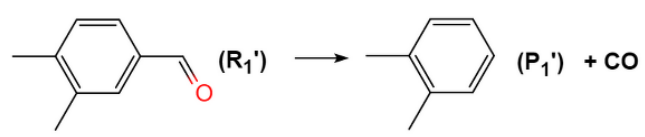

The reactant $\left(\mathrm{R}_{1^{\prime}}\right)$ with aldehyde group decomposes into the product $\left(\mathrm{P}_{1^{\prime}}\right)$ and $\mathrm{CO}$.

\subsection{DFT Calculation Results}

\subsubsection{Calculation Model}

Coal is a complex organic macromolecule with a heterogeneous chemical composition [16]. The Wiser model of coal is a reasonable and accurate chemical structure model in the field of coal chemistry. It reflects the new progress in the study of the chemical structure of coal. It can explain many chemical reactions of coal [17]. When investigating the reaction involving the local structure of molecules, some relatively small aromatic molecules, such as toluene and dibenzyl benzene, can often be used to represent the structure of coal $[18,19]$. Based on the Wise coal molecular model, and combined with the infrared analysis results, the feature part was abstracted to form the local microstructure model (see Figure 5). Then, quantum chemical calculations of the local microstructure model can reveal the relationship between the structure of the coal and the specific reaction from a microscopic perspective.

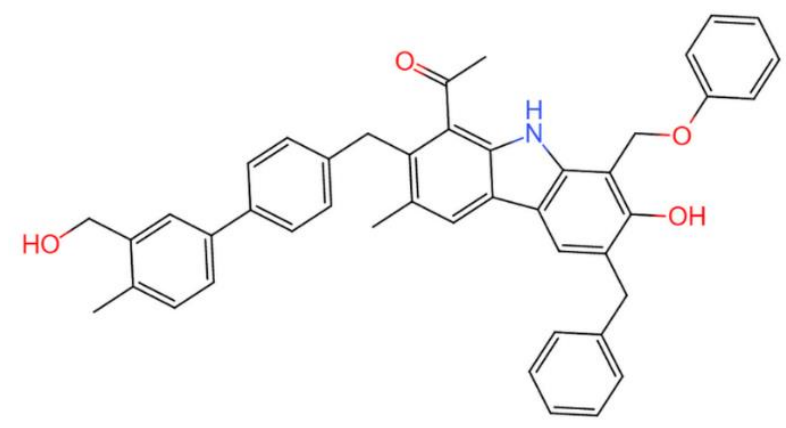

Figure 5. Simplified molecular structure of coal for quantum chemical calculations.

\subsubsection{ESP Analysis}

The reactivity of coal depends on its structure, especially on its microscopic electronic structure. The active site of the reactants can be inferred from the ESP and electron density on the surface of each molecule [20]. Based on this experimental fact, the study of ESP of molecules has been successfully applied to the researches of the relationships between structures and properties [21-23].

The REDOX reaction between coal molecules and oxygen molecules leads to the spontaneous combustion of the coal. The oxygen molecules, as oxidants, gain electrons in the reaction, and some certain functional groups of coal molecules, as reductants, lose electrons in the reaction. Therefore, it is meaningful to study the ESP of coal molecules. First, the simplified molecular structure of coal was optimized. The optimization path is shown in Figure 6.

It can be seen from Figure 6 that, after 25 steps of optimization, the total energy of the structure gradually tends to be stable and reaches the minimum value. The energy curve shows that the final structure is the optimal structure. The ESP distribution can be obtained by frequency and energy calculations based on the optimal structure. ESP mapped on the isosurface ( 0.001 a.u.) of the simplified coal molecular structure was plotted in Figure 7. Moreover, the negative potential distribution on the surface of the coal molecules can be seen in Table 2. 


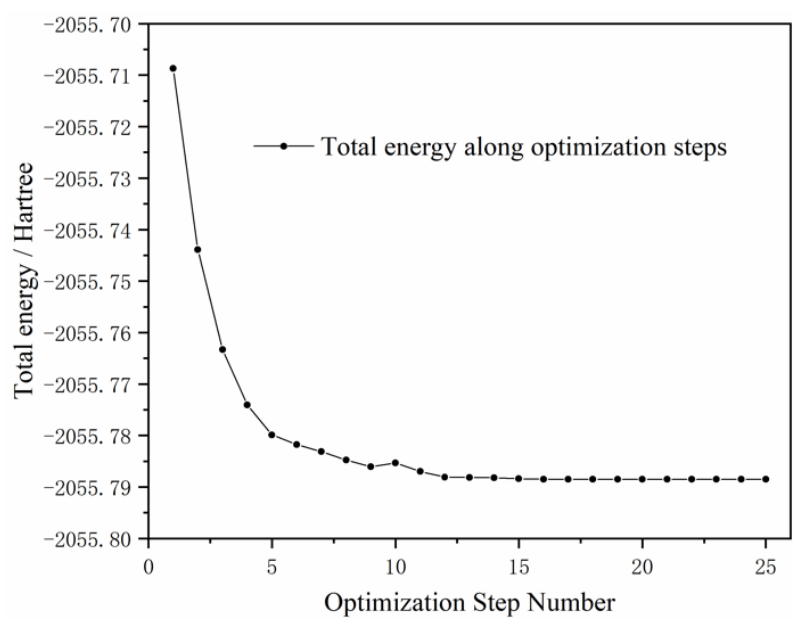

Figure 6. The total energy of coal along the optimization path.

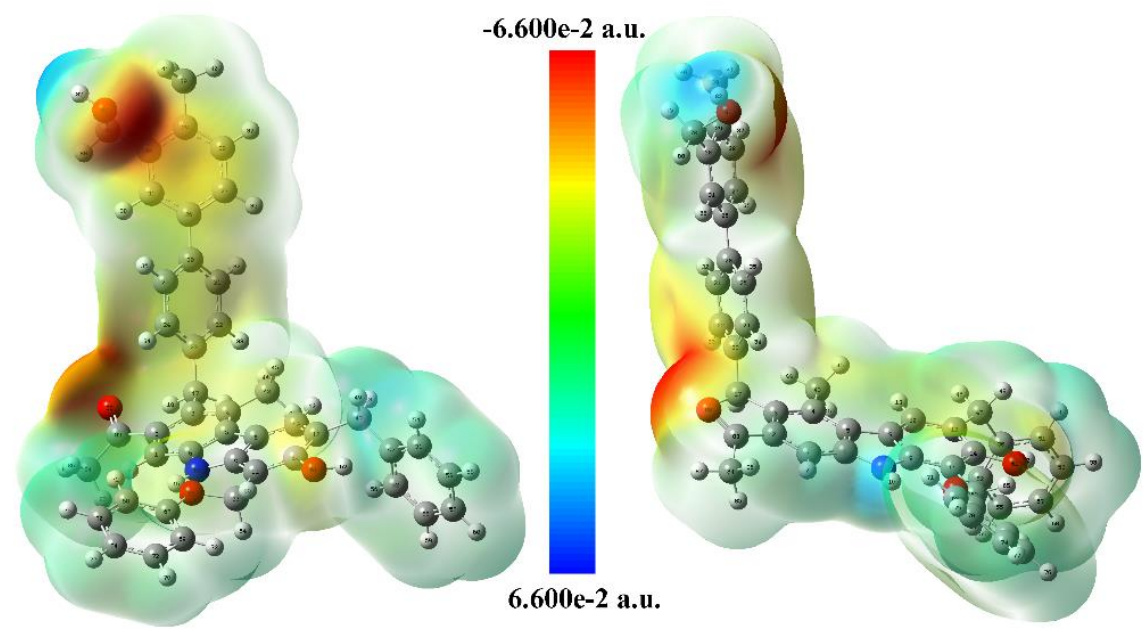

Figure 7. Front view (left) and side view (right) of electronic static potential (ESP).

Table 2. Negative potential distribution on the surface of coal molecules.

\begin{tabular}{ccc}
\hline No. & Site & Potential (a.u.) \\
\hline $1 \#$ & O81 & -0.06726 \\
$2 \#$ & O88 & -0.06628 \\
$3 \#$ & C26-31 & -0.03474 \\
$4 \#$ & C20-25 & -0.03262 \\
$5 \#$ & O66 & -0.03066 \\
$6 \#$ & O61 & -0.03013 \\
\hline
\end{tabular}

It can be seen from Table 2 that the negative potential sites mainly appear near the oxygen atoms of oxygen-containing functional groups and some benzene rings. There are large negative potential values near $\mathrm{O} 81$ and $\mathrm{O} 88$ ( -0.06726 a.u. and -0.06628 a.u., respectively). It indicates that these two functional groups are more likely to react with oxygen. The ESP analysis results are consistent with the predicted react path a and $b$.

The same conclusion can be drawn from Figure 7. We can see that there are positive and negative potential distributions on the surface of coal molecules. The side chains with hydroxyl groups attached to $\alpha$-carbon atoms have a negative electrostatic potential. The maximum is -0.06726 a.u. Due to the electron conjugation, an unshared pair of electrons in the -OH group tends to become the electron donor. Moreover, the oxygen atoms in the hydroxyl group are more electronegative than the carbon 
atoms, leading to the inductive effect of electron absorption. These two effects weaken the $\mathrm{C}-\mathrm{H}$ bond and make it easy to form stable free radicals.

Similarly, there is a negative electrostatic potential near the aldehyde group at the edge of the benzene ring. The maximum is -0.06628 a.u. The carbonyl group in the aldehyde group produces $\pi-\pi$ conjugation with the $\mathrm{C}-\mathrm{C}$ bond attached to it. Moreover, the aromatic ring produces $\pi-\pi$ conjugation with the same $\mathrm{C}-\mathrm{C}$ bond. Therefore, the positive charge of the carbonyl group disperses into the aromatic ring due to the delocalization.

According to the calculation results, the extremum of the electrostatic potential occurs near the oxygen and hydrogen atoms of the oxygen-containing functional groups (particularly near the side chains with hydroxyl groups attached to $\alpha$-carbon atoms and the aldehyde group at the edge of the benzene ring). This indicates that, compared with a benzene ring, methyl group, and other structures, oxygen-containing functional groups are more likely to react with oxygen molecules. Low metamorphic coal contains more oxygen-containing functional groups, which brings more extreme points to the surface electrostatic potential of coal molecules, thus providing more reaction sites. This conclusion is consistent with the previous studies.

\subsubsection{Energy Analysis}

The transition state structure refers to the highest point of energy in the reaction path. The reaction rate can be calculated by the height of the energy barrier. The difficulty of the reaction can be evaluated by the transition state of the reaction. The default calculation settings for temperature and pressure are $298.15 \mathrm{k}$ and $1 \mathrm{~atm}$, respectively. The enthalpy and Gibbs free energy of the molecules can be obtained by optimizing the molecular structure to the lowest energy. By optimizing the transition state to the energy saddle point (QST3), the optimized transition state, the corresponding enthalpy, and Gibbs free energy can be obtained.

Moreover, the reaction rate constant was calculated based on the transition state theory [24].

$$
k=\sigma \frac{k_{B} T}{h}\left(\frac{R T}{P}\right)^{\Delta n} e^{-\Delta E_{a} /\left(k_{B} T\right)}
$$

where $k$ is the reaction rate constant $\left(\mathrm{s}^{-1}\right)$; $\sigma$ is reaction path degeneracy (the value is 4 ); $k_{B}$ is The Boltzmann constant; $T$ is the temperature of the coal sample (K); $h$ is the Planck constant; $R$ is Gas constant; $P$ is the reaction pressure $(\mathrm{kPa}) ; \Delta E a$ is the activation energies $(\mathrm{kcal} / \mathrm{mol})$

$$
\Delta E_{a}=H_{T S}-H_{\text {Reactant }}
$$

where $\Delta E a$ is the activation energies $(\mathrm{kcal} / \mathrm{mol}) ; H_{T S}$ is the enthalpy of the transition state $(\mathrm{kcal} / \mathrm{mol})$; $H_{\text {Reactant }}$ is the enthalpy of the reactant $(\mathrm{kcal} / \mathrm{mol})$. The standard thermodynamic parameters, including enthalpy $(H)$, Gibbs free energy $(G)$, enthalpy changes $(\Delta H)$, Gibbs free energy changes $(\Delta G)$, activation energies $(E a)$, and reaction rate constant $(k)$, are summarized in Table 3.

For reaction path a, the $\Delta H$ and $\Delta G$ of step 1 and step 2 are $-61.16 \mathrm{kcal} / \mathrm{mol},-56.30 \mathrm{kcal} / \mathrm{mol}$, $-78.03 \mathrm{kcal} / \mathrm{mol}$, and $-80.38 \mathrm{kcal} / \mathrm{mol}$, respectively. This means that these two reactions are exothermic and spontaneous. Step 3 is an endothermic reaction because the $\Delta H$ is $24.02 \mathrm{kcal} / \mathrm{mol}$. The $\Delta G$ of step 3 is $19.08 \mathrm{kcal} / \mathrm{mol}$ which means that the reactions cannot take place spontaneously. The $E a$ and $k$ of step 3 show that the reaction will take place with the energy generated by step 1 and step 2 . For reaction path $\mathrm{b}$, we can conclude that it is an exothermic and spontaneous reaction by $\Delta H$ and $\Delta G$. By comparing the reaction rates, it can be seen that reaction path $b$ is more difficult than reaction path $a$. 
Table 3. Thermodynamic data of all species and activation energies of the reactions.

\begin{tabular}{|c|c|c|c|c|c|c|c|c|}
\hline Reaction I & ath & Species & $\begin{array}{l}H \\
\text { (Hartree) }\end{array}$ & $\begin{array}{l}G \\
\text { (Hartree) }\end{array}$ & $\begin{array}{l}\Delta H \\
\text { (kcal/mol) }\end{array}$ & $\begin{array}{l}\Delta G \\
(\mathrm{kcal} / \mathrm{mol})\end{array}$ & $\begin{array}{l}E a \\
(\mathrm{kcal} / \mathrm{mol})\end{array}$ & $k\left(\mathrm{~s}^{-1}\right)$ \\
\hline \multirow{9}{*}{$\begin{array}{l}\text { Reaction } \\
\text { Path a }\end{array}$} & \multirow{3}{*}{ Step 1} & $\mathrm{R}_{1}+\mathrm{O}_{2}$ & 496.8948 & 496.9468 & \multirow{3}{*}{-61.16} & \multirow{3}{*}{-56.30} & \multirow{3}{*}{16.24} & \multirow{3}{*}{$1.455 \times 10^{-9}$} \\
\hline & & $\mathrm{TS}_{1}$ & 496.8684 & 496.9209 & & & & \\
\hline & & $\mathrm{M}_{1}$ & 496.9923 & 497.0365 & & & & \\
\hline & \multirow{3}{*}{ Step 2} & $\mathrm{M}_{1}$ & 496.9923 & 497.0365 & \multirow{3}{*}{-78.03} & \multirow{3}{*}{-80.38} & \multirow{3}{*}{25.68} & \multirow{3}{*}{$3.223 \times 10^{-11}$} \\
\hline & & $\mathrm{TS}_{2}$ & 496.9462 & 496.9956 & & & & \\
\hline & & $\mathrm{R}_{2}+\mathrm{H}_{2} \mathrm{O}$ & 497.1166 & 497.1646 & & & & \\
\hline & \multirow{3}{*}{ Step 3} & $\mathrm{R}_{2}+\mathrm{H}_{2} \mathrm{O}$ & 497.1166 & 497.1646 & \multirow{3}{*}{24.02} & \multirow{3}{*}{19.08} & \multirow{3}{*}{34.55} & \multirow{3}{*}{$8.984 \times 10^{-13}$} \\
\hline & & $\mathrm{TS}_{3}$ & 497.0585 & 497.1096 & & & & \\
\hline & & $\mathrm{P}_{1}+\mathrm{H}_{2} \mathrm{O}+\mathrm{CO}$ & 497.0784 & 497.1342 & & & & \\
\hline \multirow{3}{*}{\multicolumn{2}{|c|}{ Reaction Path b }} & $\mathrm{R}_{1^{\prime}}$ & 345.5462 & 345.5839 & \multirow{3}{*}{3.87} & \multirow{3}{*}{-3.79} & \multirow{3}{*}{84.76} & \multirow{3}{*}{$1.421 \times 10^{-21}$} \\
\hline & & $\mathrm{TS}^{\prime}$ & 345.4085 & 345.4489 & & & & \\
\hline & & $\mathrm{P}_{1^{\prime}}$ & 345.5400 & 345.5900 & & & & \\
\hline
\end{tabular}

Note: $\mathrm{TS}_{1}$ means the transition state of step 1 in reaction a; $\mathrm{TS}_{2}$ means the transition state of step 2 in reaction a; $\mathrm{TS}_{3}$ means the transition state of step 3 in reaction a; TS' means the transition state of reaction $\mathrm{b}$.

From Figures 8 and 9, we can see that the Ea of the three steps in the reaction path a is $16.24 \mathrm{kcal} / \mathrm{mol}$, $25.68 \mathrm{kcal} / \mathrm{mol}$ and $34.55 \mathrm{kcal} / \mathrm{mol}$. This means the chemisorptions in step 1 will take place easily and widely. Some of the intermediate $\left(\mathrm{M}_{1}\right)$ can decompose into reactant $2\left(\mathrm{R}_{2}\right)$ with carboxy group (we have detected the increase in the carboxyl group by FTIR), and less reactant $2\left(\mathrm{R}_{2}\right)$ continue to decompose into product $1\left(\mathrm{P}_{1}\right)$ and $\mathrm{CO}$; The $E a$ of reaction path $\mathrm{b}$ are $84.76 \mathrm{kcal} / \mathrm{mol}$. They are higher than the $E a$ in reaction path a. But it will not be too hard to make the reaction take place with the energy generated by reaction path $a$.

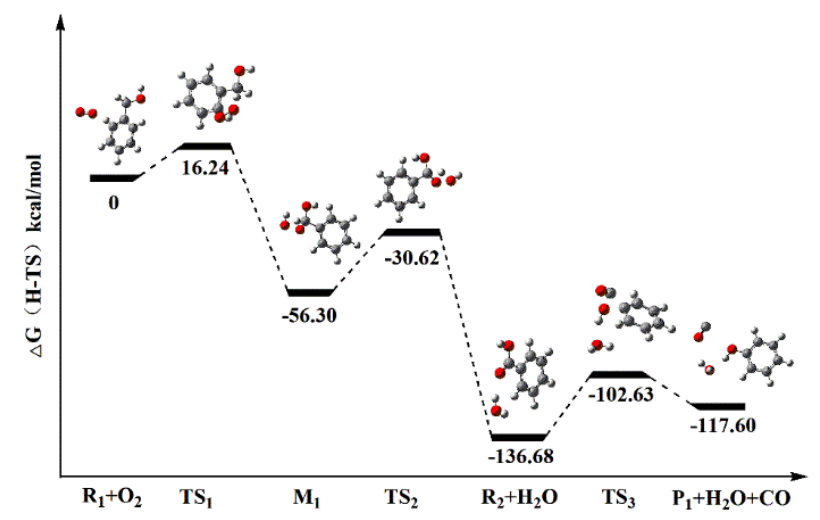

Figure 8. Sketch map of the reaction potential energy profile of reaction path a.

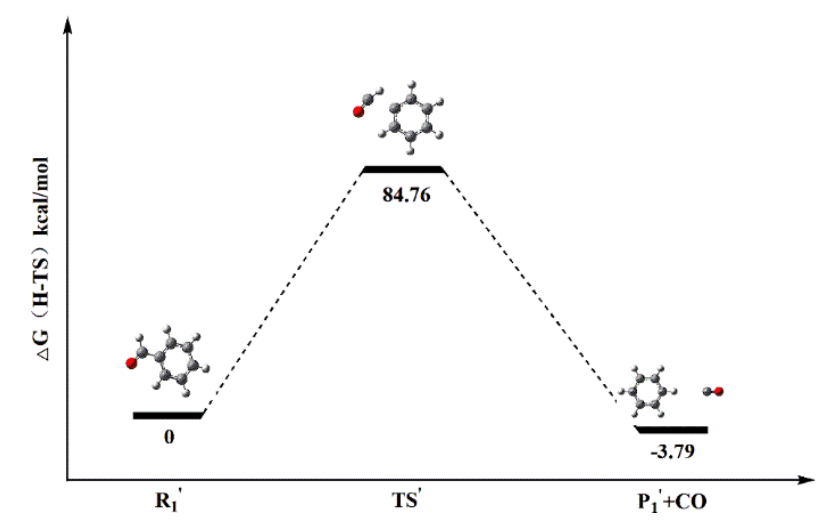

Figure 9. Sketch map of the reaction potential energy profile of reaction path $b$. 


\section{Conclusions}

Coal can react with oxygen and generate $\mathrm{CO}$ under ambient temperature. The $\mathrm{CO}$ formation rules of AW coal under ambient temperature were analyzed by self - developed coal oxidation device. During the experiment, the maximum concentration level of CO can be $389 \mathrm{ppm}$ after $79 \mathrm{~h}$. The FTIR comparison test shows that methylene and aldehyde groups involved in the reaction. The carboxy is a key functional group for coal to produce $\mathrm{CO}$, and it was detected as an intermediate in the oxidation reaction. There would be some interesting findings if we can associate the generation of carboxyl groups with the spontaneous combustion tendency of coal. This is well worth pursuing further. Based on the FTIR results and combined with previous research, the possible reaction paths were concluded for AW coal oxidation to produce $\mathrm{CO}$ under ambient temperature. The ESP calculation showed that the side chains with hydroxyl groups attached to $\alpha$-carbon atoms and the aldehyde group at the edge of the benzene ring are the possible reaction sites. The standard thermodynamic parameters of the molecules along the predicted reaction paths were calculated, and the results show that the experiment can be carried out spontaneously under ambient temperature. This study may be helpful in understanding the rule of coal oxidation under ambient temperature. This research theoretically proved that coal could be oxidized to carbon monoxide under ambient temperature. Furthermore, under certain conditions, $\mathrm{CO}$ can accumulate to a very high concentration. The results of the experiment and analysis show that the presence of a certain concentration of $\mathrm{CO}$ under the coal mine may not be caused by a serious fire. The warning value of carbon monoxide needs to be evaluated, respectively. This is of considerable significance to guide coal mine safety management.

Author Contributions: Formal analysis, C.Z. and Y.Z.; Methodology, J.W.; Writing-original draft, S.L.; Writing-review \& editing, Y.W. All authors have read and agreed to the published version of the manuscript.

Funding: The authors gratefully acknowledge the financial support of the National Science Foundation for Young Scientists of China (51704207), the Shanxi Province Key R\&D Program (International Cooperation) Project (201803D421105), and the Shanxi Province Applied Basic Research Program Project (201901D111073).

Acknowledgments: The authors wish to thank the Taiyuan University of Technology (TYUT) for the support of this work. The authors also wish to thank the co-workers and technical staff at the University of Wollongong (UOW) to provide coal samples and laboratory equipment.

Conflicts of Interest: The authors declare no conflict of interest. The founding sponsors had no role in the design of the study; in the collection, analyses, or interpretation of data; in the writing of the manuscript; and in the decision to publish the results.

\section{References}

1. Song, Z.; Kuenzer, C. Coal fires in China over the last decade: A comprehensive review. Int. J. Coal Geol. 2014, 133, 72-99. [CrossRef]

2. Xie, J.; Xue, S.; Cheng, W.; Wang, G. Early detection of spontaneous combustion of coal in underground coal mines with development of an ethylene enriching system. Int. J. Coal Geol. 2011, 85, 123-127. [CrossRef]

3. Xu, Q.; Yang, S.; Tang, Z.; Cai, J.; Zhong, Y.; Zhou, B. Free Radical and Functional Group Reaction and Index Gas CO Emission during Coal Spontaneous Combustion. Combust. Sci. Technol. 2017, 190, 834-848. [CrossRef]

4. Yuan, L.; Smith, A.C. $\mathrm{CO}$ and $\mathrm{CO}_{2}$ emissions from spontaneous heating of coal under different ventilation rates. Int. J. Coal Geol. 2011, 88, 24-30. [CrossRef]

5. Gu, H.-L.; Yu, M.-G.; Xu, Y.-L. Analysis on the genetic type and mechanism identification of carbon monoxide in the coalmine. J. China Coal Soc. 2013, 38, 1812-1818.

6. Wang, H.-H.; Dlugogorski, B.; Kennedy, E. Analysis of the mechanism of the low-temperature oxidation of coal. Combust. Flame 2003, 134, 107-117. [CrossRef]

7. Yanni, Z.; Long, C.; Deng, J.; Zhao, J. Study on Thermal Effect of Coal Oxidation at Low-Temperature. In Proceedings of the 11th International Mine Ventilation Congress; Chang, X., Ed.; Springer: Berlin/Heidelberg, Germany, 2019; pp. 552-559. 
8. Zhang, Y.; Wu, J.; Chang, L.; Wang, J.; Xue, S.; Li, Z. Kinetic and thermodynamic studies on the mechanism of low-temperature oxidation of coal: A case study of Shendong coal (China). Int. J. Coal Geol. 2013, 120, 41-49. [CrossRef]

9. Wang, J.R.; Deng, C.B.; Deng, H.Z.; Lu, W.D. Coal Surface Physical Adsorption to Oxygen Molecules Mechanism. Coal Convers. 2007, 30, 18-21.

10. Wang, D.-M.; Xin, H.-H.; Qi, X.-Y.; Dou, G.; Qi, G.-S.; Ma, L.-Y. Reaction pathway of coal oxidation at low temperatures: A model of cyclic chain reactions and kinetic characteristics. Combust. Flame 2015, 163, 447-460. [CrossRef]

11. Deng, J.; Zhao, J.; Zhang, Y.; Huang, A.; Liu, X.; Zhai, X.; Wang, C. Thermal analysis of spontaneous combustion behavior of partially oxidized coal. Process Saf. Environ. Prot. 2016, 104, 218-224. [CrossRef]

12. Wu, Y.; Zhang, Y.; Zhou, C.; Wang, J.; Wu, J.; Ren, T. Study of CO Sources and Early-warning Concentration of Spontaneous Combustion at Air Return Corner in Fully Mechanized Mining Faces. Combust. Sci. Technol. 2019, 1-18. [CrossRef]

13. Niu, Z.; Liu, G.; Yin, H.; Zhou, C.; Wu, D.; Yousaf, B. In-situ FTIR study of reaction mechanism and chemical kinetics of a Xundian lignite during non-isothermal low temperature pyrolysis. Energy Convers. Manag. 2016, 124, 180-188. [CrossRef]

14. Truhlar, D.; Hase, W.; Hynes, J. Current status of transition-state theory. J. Phys. Chem. 1983, 87, $2664-2682$. [CrossRef]

15. Anning, Z.; Lingmei, G.; Shucai, G. In The study of the structure and characteristic of coal-based functional material, United States, 1997-12-31. In Proceedings of the Pittsburgh Coal Conference, Pittsburgh, PA, USA, 23-27 September 1997.

16. Swaine, D.J. The organic association of elements in coals. Org. Geochem. 1992, 18, 259-261. [CrossRef]

17. Jurkiewicz, A. Spatial system of the Wiser model of coal structure according to the second moment of the nuclear magnetic resonance line. J. Appl. Phys. 1987, 62, 3892-3897. [CrossRef]

18. Ades, H.; Subbaswamy, K. Theoretical modeling of coliquefaction reactions of coal and polymers. Fuel Process. Technol. 1996, 49, 207-218. [CrossRef]

19. Sato, Y.; Inaba, A.; Uemasu, I.; Kushiyama, S. Fundamental study of the effect of hydrogen donor solvent on coal liquefaction. Fuel Process. Technol. 1986, 14, 67-78. [CrossRef]

20. Ke-Chang, X.; Wen-Ying, L.; Jie, F. Sulfur capture behaviour of calcia for steam or carbon dioxide gasification of coal macerals. Fuel 1993, 72, 725-726. [CrossRef]

21. Murray, J.; Abu-Awwad, F.; Politzer, P. Prediction of Aqueous Solvation Free Energies from Properties of Solute Molecular Surface Electrostatic Potentials. J. Phys. Chem. A 1999, 103, 1853-1856. [CrossRef]

22. Murray, J.; Brinck, T.; Politzer, P. Relationships of Molecular Surface Electrostatic Potentials to Some Macroscopic Properties. Chem. Phys. 1996, 204, 289-299. [CrossRef]

23. Dano, M.; Viglašová, E.; Galamboš, M.; Rajec, P.; Novák, I. Sorption behaviour of pertechnetate on oxidized and reduced surface of activated carbon. J. Radioanal. Nuclear Chem. 2017, 314, 2219-2227. [CrossRef]

24. Liu, G.; Hei, E. Definition of activation energy of chemical reaction and its relationship with the potential barrier. Univ. Chem. 2013, 5, 73-76.

(C) 2020 by the authors. Licensee MDPI, Basel, Switzerland. This article is an open access article distributed under the terms and conditions of the Creative Commons Attribution (CC BY) license (http://creativecommons.org/licenses/by/4.0/). 